\title{
Ureteric Injuries after Hysterectomy in a Tertiary Care Center of Nepal: A Descriptive Cross-sectional Study
}

\author{
Ratna Adhikari Khatri, 'Arju Chand, 'Sumana Thapa, 'Shailaja Khadka, ${ }^{1}$ Manish Thapa ${ }^{2}$ \\ 'Department of Obstetrics and Gynecology, Shree Birendra Hospital, Chhauni, Kathmandu, Nepal, ${ }^{2}$ Department \\ of Radiology, Shree Birendra Hospital, Chhauni, Kathmandu, Nepal.
}

\section{ABSTRACT}

Introduction: Pelvic surgery is the most common cause of iatrogenic ureteral injury. The incidence of ureteric injuries varies between skilled and inexperienced surgeons. The study aims to determine the prevalence of ureteric injuries sustained during hysterectomy in a tertiary care center of Nepal.

Methods: A descriptive cross-sectional study involving the women attending the gynecological outpatient department of a tertiary care center of Nepal, for various benign and malignant conditions and later on underwent hysterectomy from June 2019 to June 2020 was done after obtaining ethical clearence from the Institutional Review Committee (Reference No. 245). Convenient sampling method was used. The data were entered in Excel and analyzed using Statistical Package for Social Sciences version 17. Point estimate at 95\% Confidence Interval was calculated along with frequency and proportion for binary data.

Results: Altogether, 1 (0.63\%) (0.55-0.71 at 95\% Confidence Interval) out of 159 patients sustained the ureteric injury during hysterectomy in a tertiary care center of Nepal. The injury was seen during the exploratory laparotomy for adnexal mass. The injury was recognized intraoperatively and was repaired with double J stenting. A total of 159 patients were enrolled in the study that had undergone hysterectomy over one year for various benign and malignant conditions. Out of which 21 (13.2\%) had undergone surgeries for malignant conditions and $138(86.79 \%)$ for benign conditions.

Conclusions: Iatrogenic ureteric is still a major cause of harm and concern in hysterectomy. Patients with ureteric injury should be evaluated and intervened at the earliest.

Keywords: hysterectomy; iatrogenic; injury; ureter.

\section{INTRODUCTION}

The incidence of ureteric injury is reported to be 0.5 to $1.0 \%$ in surgery of benign diseases ${ }^{1-3}$ and 5 to $30 \%$ in surgery of malignant diseases like radical hysterectomy. ${ }^{2}$ Ureteric injury is reported more when patients have associated factors like endometriosis, pelvic infection, huge pelvic masses, previous abdominopelvic surgery, and radiation therapy.,5-6 Ligation and transaction injuries are the most common type, and other forms are thermal injury, kinking, de-vascularization, partial/ complete transaction, and perforation..$^{7-8}$

latrogenic ureteral injury is a serious complication of gynecologic surgery. The idenfication of these injuries needs to be done on time which will allow the immediate repair of these injuries, reduce morbidity, and decrease the chances of the medico-legal outcome. To our knowledge, such study hasn't been conducted in any hospitals of Nepal till date.

The study aims to find out the prevalence of ureteric injuries sustained during hysterectomy in a tertiary care center of Nepal.

Correspondence: Dr. Ratna Adhikari Khatri, Department of Obstetrics \& Gynecology, Shree Birendra Hospital, Chhauni, Kathmandu, Nepal. Email: ratnakhatri72@gmail.com, Phone: $+977-9841328007$. 


\section{METHODS}

This descriptive cross-sectional study was conducted in Shree Birendra Hospital (SBH), a tertiary level hospital in Kathmandu, Nepal. The Institutional Review Committee of the Nepalese Army Institute of Health Sciences approved the study (Reference No. 245), and informed written consent was obtained from all the patients before enrolment. This study included women visiting the Gynecology outpatient department of $\mathrm{SBH}$ with benign and malignant indications to undergo an elective hysterectomy in one year between June 2019 to June 2020. Laparoscopic hysterectomy were excluded from the study. The sample size was calculated as follows:

$\mathrm{n}=\mathrm{Z}^{2} \times \mathrm{p} \times \mathrm{q} / \mathrm{e}^{2}$

$=(1.96)^{2} \times 0.5 \times(1-0.5) /(0.09)^{2}$

$=119$

Where,

$\mathrm{n}=$ minimum required sample size

$\mathrm{Z}=\mathbf{1 . 9 6}$ at $95 \%$ Confidence Interval (Cl)

$\mathrm{p}=$ prevalence taken as $50 \%$ for maximum sample size

$q=1-p$

$\mathrm{e}=$ margin of error, $9 \%$

The calculated sample size was calculated to be 119 . Adding $10 \%$ as a non-response rate, the minimum required sample size was 131 . We took data from 159 patients. Convenient sampling method was used.

The data was collected using a semi-structured questionnaire consisting of variables such as age at the time of surgery, indication for surgery, type of surgery performed, type and time when the injury was identified, method of repair, and outcome of the repair. The data was obtained from the patient by interviewing, from case files, operating theatre details, surgical and gynecological ward registries. Visualization of ureteric peristalsis and pooling of urine in the operating field was the initial intraoperative method to detect injury during the procedure. The injury identified at the table was repaired during the primary surgery by the attending gynecologist and urosurgeon.

The data were entered in Excel and analyzed using Statistical Package for Social Sciences (SPSS) version 17.

\section{RESULTS}

Altogether, 1 (0.63\%) (0.55-0.71 at 95\% Confidence Interval) out of 159 patients sustained the ureteric injury after hysterectomy in our study. The injury was seen during the exploratory laparotomy for adnexal mass.

There were 159 patients in the study group. The average age of the patients was 48 years ranging from 32 years to 73 years. The most common surgery was total abdominal hysterectomy 72 (45.28\%), followed by vaginal hysterectomy 39 (24.52\%). About 27 (16.98\%) patients underwent exploratory laparotomy where one case was met with a ureteric injury (Figure $1)$.

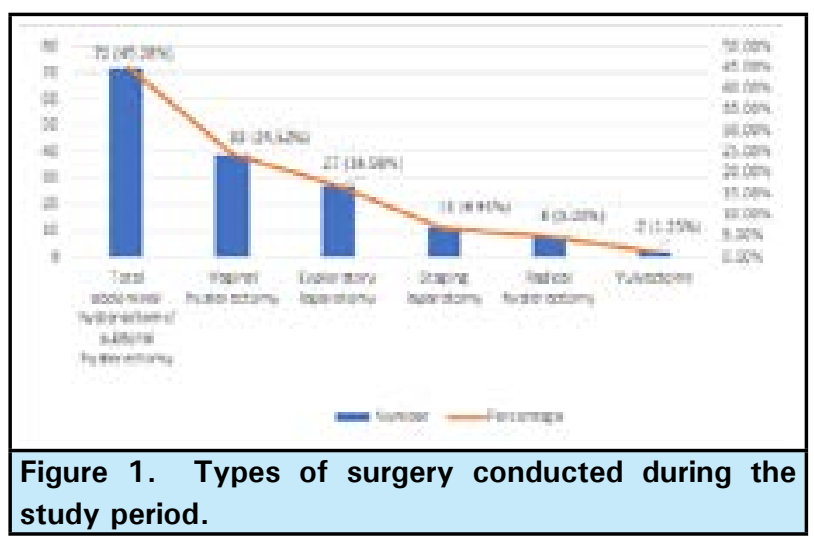

Altogether, $1(0.63 \%)$ patient sustained the ureteric injury.

Twenty-one (13.2\%) had undergone elective hysterectomy surgeries for malignant conditions and $138(86.79 \%)$ for benign conditions. The group of benign conditions included uterine prolapse 39 $(24.52 \%)$, uterine fibroids 34 (21.38\%), benign adnexal masses 27 (16.98\%), menstrual disorders 24 $(15.09 \%)$, and endometriosis $7(4.40 \%)$. The group of malignant conditions was limited to ovarian cancer $8(5.03 \%)$, cervical cancer $8(5.03 \%)$, endometrial cancer $3(1.88 \%)$, molar pregnancy $3(1.88 \%)$, vulval cancer $2(1.25 \%)$. The study distinguished between the open procedures followed for benign conditions and malignant conditions. Benign conditions had undergone total abdominal hysterectomy, subtotal hysterectomy, vaginal hysterectomy, and exploratory laparotomy. Among malignant conditions, the surgical operations conducted were staging laparotomy, radical hysterectomy, and vulvectomy (Figure 2).

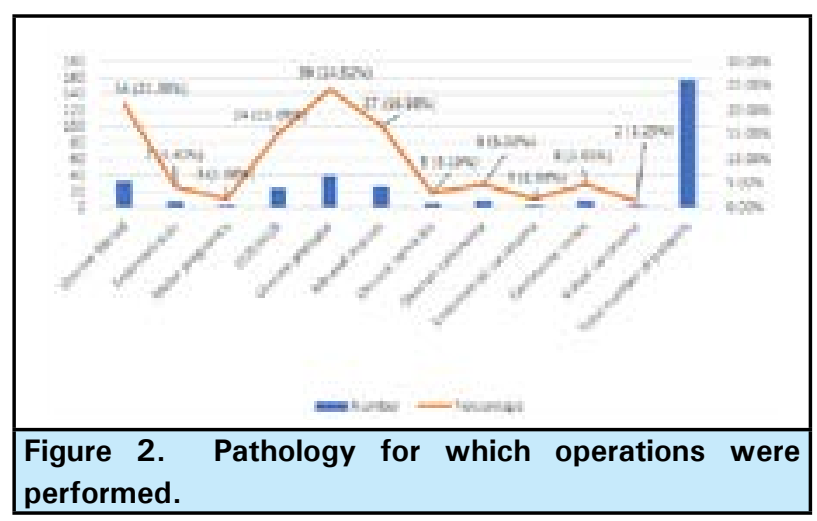

DISCUSSION

latrogenic injury to the ureter is the most common complication of abdominopelvic surgery, ranging from less than 1 to 10 percent of procedures, depending 
Khatri et al. Ureteric Injuries after Hysterectomy in a Tertiary Care Center of Nepal: A Descriptive Cross-sectional Study...

upon the complexity of the procedure..$^{9-11}$ In this study, the iatrogenic ureteric injury was reported in $0.63 \%$ of all types of hysterectomy, a figure which is comparable with other literature. ${ }^{10,11}$ However, the figure of $0.63 \%$ towards the lower side of the studies in the literature may probably be that the trained gynecologists perform all hysterectomies in our institution and another factor may be the laparoscopic hysterectomy is excluded from the study. Gynecologic laparoscopic procedures account for more than half of the injuries, and the most common location is the lower ureter. ${ }^{5,12}$ The injury or fistula may become apparent either immediately or much more commonly, in a delayed fashion several days to weeks after surgery. However, a high index of suspicion with symptoms such as flank pain and fever may suggest ureteric injury after pelvic surgery. Complete transaction of the ureter causes immediate leakage of urine within first 24-48 hours of surgery, while ligation and thermal injury present later following tissue necrosis.

The ureteric injury sustained in this study was following exploratory laparotomy with hysterectomy done for adnexal mass in 73 years old patient. The injury was identified intraoperatively by urinary extravasations into the retroperitoneal space. Similar to the study conducted by Patil SB, et al. open hysterectomy for benign diseases was the cause of ureteric injury. ${ }^{5}$ The time of recognition of injury is crucial. Intraoperative recognition of ureteric injury is very low ranges from $11-33 \%$. If they are identified pre-operatively, they can be repaired quite easily. Otherwise, if these injuries are identified late, patients do present with anuria, renal failure, and urinary fistula. In Khizar Hayat, et al. study, $28.56 \%$ patients' injury was identified at the table and managed accordingly. A similar review conducted in eastern Nigeria found ligation and transaction the most common form of injury. ${ }^{4,7}$

The risk factors for iatrogenic injury include nature and indication of the abdominal or pelvic surgery, patientrelated factors such as pelvic adhesions from previous surgeries, history of pelvic radiation, enlarged uterus, pelvic malignancy, pelvic endometriosis, and anatomical abnormalities. ${ }^{9,13,14}$ In the present study, the cause of injury was pelvic adhesion with the retroperitoneal adnexal mass and found to have inadvertent ureter.
The experience of the operating surgeon may also be an important risk factor. ${ }^{15-6}$ Keeping this in mind, the hysterectomies in our institution are all conducted by experienced surgeons. This may be why we had a smaller number of iatrogenic ureteric or bladder injuries and an injury identified intraoperatively.

Similar to our study, Blackwell $\mathrm{RH}$, et al. reported 81 percent of those who underwent hysterectomy for benign indications. The ureteral injury occurred in less than 1 percent of patients $(0.78 \%)$ and was unrecognized in 62 percent of cases. ${ }^{17}$ While there was no significantly increased risk of acute renal failure or death for unrecognized ureteral injuries compared with no injuries, the unrecognized injury was associated with a nearly 24-fold increased risk of acute renal failure and 40 percent increased odds for death.

The patient with ureteric injury should be evaluated and intervened at the earliest within two weeks after hysterectomy because it has higher chances of success with endourological procedures, obviating the need for open surgery. ${ }^{5}$ Thus, to detect any unrecognized injuries, apart from this study, all patients were reviewed and followed up with clinical evaluation, urine routine examination, and ultrasound abdominopelvic in 2 weeks and a month later to detect the problem at the earliest and tackle it to prevent morbidity and mortality.

As this study is conducted in one institution and confined to one population, the findings cannot be generalized. More extensive studies need to be undertaken related to this subject for better analysis.

\section{CONCLUSIONS}

Our study revealed that a simple hysterectomy for a benign disease could be the cause of ureteral injury. Intraoperative evaluation of the ureter during vaginal procedures is more difficult given the limited operating field and anatomic distortion. Cystoscopy is a simple procedure to evaluate a silent injury to the urinary system. The adoption of universal cystoscopy after all hysterectomies is recommended. This will allow the immediate repair of these injuries, reduce morbidity, and decrease the chances of the medico-legal outcome.

\section{Conflict of Interest: None.}

\section{REFERENCES}

1. Hayat K, Alam M, Jafari SA, Husain S. Iatrogenic bilateral ureteric injuries a complication during pelvic surgeries. Pak J Med Heal Sci. 2016;10(3):677-80. [Full Text]

2. Shaw MB, Tomes M, Rix DA, Dorkin TJ, Murthy LN, Pickard RS. The management of bilateral ureteric injury following radical hysterectomy. Adv Urol. 2008;2008:524919. [PubMed | Full Text | DOI]
3. St Lezin MA, Stoller ML. Surgical ureteral injuries. Urology. 1991 Dec;38(6):497-506. [PubMed | Full Text | DOI]

4. Lawal O, Bello O, Morhason-Bello I, Abdus-Salam R, Ojengbede $\mathrm{O}$. Our experience with iatrogenic ureteric injuries among women presenting to university college hospital, Ibadan: a call to action on trigger factors. Obstet 
Gynecol Int. 2019 Feb 10;2019:6456141. [랄ed | Full Text | DOI]

5. Patil SB, Guru N, Kundargi VS, Patil BS, Patil N, Ranka K. Posthysterectomy ureteric injuries: Presentation and outcome of management. Urol Ann. 2017 Jan-Mar;9(1):4-8. [ubMed | Full Text | DOI]

6. Kumar D, Gupta N. Post- hysterectomy ureteric injuries: presentation and outcome of management in a tertiary care centre. Int J Sci Res. 2019;8(4):36-8. [Full Text | DOI]

7. Nnabugwu I, Amu O. Iatrogenic ureteric injuries complicating open obstetric and gynaecologic operations in South East Nigeria - case series. J West Afr Coll Surg. 2011 Jul;1(3):98-108. [PubMed | Full Text]

8. Kiran A, Hilton P, Cromwell DA. The risk of ureteric injury associated with hysterectomy: a 10-year retrospective cohort study. BJOG. 2016 Jun;123(7):1184-91. [․ㅏbMed | Full Text | DOI]

9. Chalya PL, Massinde AN, Kihunrwa A, Simbila S. Iatrogenic ureteric injuries following abdomino-pelvic operations: a 10-year tertiary care hospital experience in Tanzania. World J Emerg Surg. 2015 Mar 12;10:17. [PubMed | Full Text | DOI]

10. Carver BS, Bozeman CB, Venable DD. Ureteral injury due to penetrating trauma. South Med J. 2004 May;97(5):462-4. [PubMed | Full Text | DOI]

11. Al-Awadi K, Kehinde EO, Al-Hunayan A, Al-Khayat A. Iatrogenic ureteric injuries: incidence, aetiological factors and the effect of early management on subsequent outcome. Int Urol Nephrol. 2005;37(2):235-41. [ubMed | Full Text | $\underline{\mathrm{DOI}}$
12. Parpala-Sparman T, Paananen I, Santala M, Ohtonen P, Hellstrom P. Increasing numbers of ureteric injuries after the introduction of laparoscopic surgery. Scand J Urol Nephrol. 2008;42(5):422-7. [PubMed | Full Text | DOI]

13. Chou MT, Wang CJ, Lien RC. Prophylactic ureteral catheterization in gynecologic surgery: a 12-year randomized trial in a community hospital. Int Urogynecol J Pelvic Floor Dysfunct. 2009 Jun;20(6):689-93. [라Med | Full Text | DOI]

14. Kim JH, Moore C, Jones JS, Rackley R, Daneshgari F, Goldman H, Vasavada S. Management of ureteral injuries associated with vaginal surgery for pelvic organ prolapse. Int Urogynecol J Pelvic Floor Dysfunct. 2006 Sep;17(5):531-5. [PubMed | Full Text | DOI]

15. Hammad FT, Al Qaiwani KM, Shirodkar SS. The role of urologists in the management of urological injuries during obstetric and gynaecologic surgery. Int Urogynecol J. 2010 Oct;21(10):1237-41. [PubMed | Full Text | DOI]

16. Schimpf MO, Gottenger EE, Wagner JR. Universal ureteral stent placement at hysterectomy to identify ureteral injury: a decision analysis. BJOG. 2008 Aug;115(9):1151-8. [PubMed | Full Text | DOI]

17. Blackwell RH, Kirshenbaum EJ, Shah AS, Kuo PC, Gupta GN, Turk TMT. Complications of recognized and unrecognized iatrogenic ureteral injury at time of hysterectomy: A population based analysis. J Urol. 2018 Jun;199(6):1540-5. [PubMed | Full Text | DOI]

This work is licensed under a Creative Commons Attribution 4.0 International License. The images or other third party material in this article are included in the article's Creative Commons license, unless indicated otherwise in the credit line; if the material is not included under the Creative Commons license, users will need to obtain permission from the license holder to reproduce the material. To view a copy of this license, visit http://creativecommons.org/licenses/by/4.0/ 